\author{
홀가먼트의 생산 공정과 니트웨어 개발 사례 ${ }^{+}$ \\ - SWG-X 기종을 중심으로 - \\ 이인숙 - 조규화 - 김지영 * \\ (주)마리오 까르뜨니트 디자인 실장 \\ 이화여자대학교 명예교수 \\ 충북대학교 패션디자인정보학과 부교수*
}

\title{
The Production Process of Whole Garments and the Development Case of Knitwear \\ - Focused on the SWG-X machine -
}

\author{
Lee Insuk - Cho Kyuhwa - Kim Jiyoung * \\ Department Manager, Dept. of Fashion Design, CARTE KNIT of MARIO Co., Ltd. \\ Emeritus Professor, Ewha Womans University \\ Associate Professor, Dept. of Fashion Design Information, Chungbuk National University*
}

\begin{abstract}
The purpose of this study is to summarize systematically and understand the characteristics of the production process of whole garments in order to develop knitwear using a real whole garment machine and propose this as a development case for high value added knitwear design.

Concerning research methods, the study looked at existing research into whole garment knitwear and relevant data, data on websites, and the whole garment knitting machine made by Shima Seiki, a Japanese company, which has been the most commonly used machine in Korea.

Also the study collected program data concerning a knitting machine and knitting by participating in the production process of whole garment knitwear, and the production line was filmed directly. In addition, the study conducted research into the development of knitwear design using the SWG-X 12 gauge.
\end{abstract}

\footnotetext{
+ 본 논문은 박사학위논문의 내용을 부분 발췌한 것입니다.

Corresponding author: Kim Jiyoung, Tel. +82-43-261-2783 Fax +82-43-274-2792

E-mail:coco7@cbnu.ac.kr
} 
The conclusions obtained from the production process of whole garments and product development include the following. First, whole garment knitwear is appropriate for expressing a sophisticated look that makes the body appear to be in one form through natural connection without any seam allowance. Second, it is very suitable for response production since it does not go through the pattern, cutting, and processing stages. Furthermore, because of the consistent management of the entire process by computer control, it may be the highest cutting-edge fashion area in which planning and proposal style industry may be realizable. Third, it is easy to approach design through a programming process, and it is possible to develop diverse patterns; thereby, it is appropriate for producing high value added knitwear products.

Key Words : Whole Garment(홀가먼트), Production Process(생산 공정), Knit Wear(니트웨어), Seamless Knit(무봉제 니트)

\section{I. 서 론}

니트웨어 산업은 기계, 기술의 발달과 함께 많은 변화를 거듭해 오고 있다. 1860 년대의 재봉틀 발명 이후, 현재까지 의류 제조 기술의 중심을 이룬 재단 과 봉제에 의한 제조 방식은 바늘과 가위를 전혀 사 용하지 않은 봉제선이 없는 획기적인 무봉제 (Seamless Garments) ${ }^{1)}$ 제조공정으로 진화하고 있 다. ${ }^{2)}$ 1995년 이탈리아 밀라노에서 개최된 국제 섬 유기계 전시회인 $\mid \mathrm{TMA}^{3}$ 에서 일본의 시마 세이키 (Shima Seiki)사가 무봉제 니트편기인 홀가먼트 (Whole Garment) $)^{4}$ 를 처음 발표하면서 무봉제 니트 웨어가 현실화 되었으며 소비자의 욕구를 충족시킬 제품들이 개발, 생산되고 있다. 선진국의 니트 제조 업체들은 기술 개발을 통하여 신제품을 출시하고 있 으며 소비자 기호의 변화에 따라 끊임없이 새로운 니트 기술을 개발하고 있다. ${ }^{5}$

무봉제 니트는 니트 편직기 발달과정의 최정점에 있는 것으로 1965년 시마세이키사의 무봉제 장갑 편직기를 시작으로 1995년 무봉제 니트웨어 편직기 '홀가먼트'를 통해 어패럴분야까지 확장되었다. ${ }^{6)}$ 최 근에는 우주선 실내복으로 선정되는 등 최첨단 과학 기술이 요구되는 테크니컬 웨어까지 그 영역이 넓어 지고 있다. ${ }^{7)}$

홀가먼트(Whole Garment) 니트웨어는 편직기계에 서 한 벌의 옷이 완성되어 봉제과정을 거치지 않고 나오는 최신의 니트 제품으로서 소재 본래의 신축성
을 유지하는 동시에 운동성과 저부하성을 겸비하여 편안한 니트웨어의 본질에 가장 가까이 근접한 형태 라 할 수 있다. 홀가먼트 니트웨어는 고급화, 개성 화 되어가는 소비자의 욕구를 충족시켜 줄 수 있으 며 고부가가치 디자인 개발을 위한 방안이 될 수 있 다.

그러나 홀가먼트 편기는 일반 횡편기의 2 배 정도 의 기계설비 투자가 들기 때문에 국내에는 편직 업 체수가 극히 적은편이다. 기계 투자비용이 높기 때 문에 자연히 편직료가 높아지고 이것은 곧 생산력 저하로 이어져 아직까지 국내 소비자에게 홀가먼트 니트웨어의 인지도는 낮은 실정이다.

이에 본 연구의 목적은 홀가먼트의 생산 공정을 살펴보고 실제 디자인 개발을 실시함으로써 홀가먼 트 니트웨어를 알리는데 기여하고 홀가먼트 니트웨 어 디자인에 관한 기초 자료를 제공하는데 있다.

연구방법으로는 선행연구와 관련 자료를 통한 문 헌고찰과 홀가먼트 제작 현장의 조사 및 참여를 통 한 실질적인 접근을 병행하였다. 국내에서 보편적으 로 사용되는 일본 시마세이키(島精機, Shima Seiki) 사 홀가먼트 편기인 SWG-X 12게이지를 대상으로 홀가먼트 니트웨어 생산 공정에 참여하여 생산현장 을 직접 촬영하였고 편직기 및 편직관련 프로그램자 료를 수합하여 자료로 제시하였다. 또한 생산 공정 에 따라 홀가먼트 니트웨어를 개발하여 생산 공정의 자료로 제시하였다.

용어 표기에 있어 무봉제 니트 중에서도 홀가먼트 
편기로 제작된 제품은 홀가먼트로 표기하였고, 재단 봉제는 컷 앤 소, 재단과 링킹은 컷 앤 링킹, 성형 편은 풀 패셔닝으로 통일하였다.

\section{II. 공정에 따른 니트 제품의 구분}

일반적으로 니트 제품은 봉제 방법과 편직 공정에 의 해 구분되는데, 재단봉제 방법인 컷 앤 소(Cut \& Sew), 컷 앤 링킹(Cut \& Linking)과 부분 공정이 들어 가는 풀 패셔닝(Full Fashioning), 인터그랄 니트 (Integral Knit), 무봉제 니트(Seamless Knit)로 나눈 다. ${ }^{8)}$

\section{1. 컷 앤 소(Cut \& Sew)}

컷 앤 소는 저지와 같은 편성물 상태로 편직된 원단 을 재단, 봉제하여 만드는 방법이다<Figure 1>. 이 방 법은 니트 제품을 편직하는데 높은 기술을 요구하지
않으나, 패턴을 사용하기 때문에 니트의 특성을 알고 패턴을 사용하여야 하는 기술적인 방법이 요구된다. 일반적으로 직물을 봉제하는 과정과 거의 비슷하며, 재봉기를 사용하여 봉제하느냐, 링킹기를 사용하여 봉 제하느냐에 따라서 달라진다. 풀리 컷(fully cut)이라고 도 하며 입체적인 디자인에 적합하다. ${ }^{9}$

\section{2. 컷 앤 링킹(Cut \& Linking)}

컷 앤 링킹은 환편기나 횡편기에서 편직된 원단을 재 단봉제 하는 제품으로 칼라, 소매입구, 앞단 등을 링킹 봉제하는 것이다. <Figure 2>는 몸판과 소매의 각 부 분을 따로 편직하고 재단해서 봉제하는 방법이다. 횡 편기에서 단 부분을 단짜기부터 짜고 나서, 몸판 짜기 와 소매 짜기를 한 원단을 재단하고, 깃과 칼라와 앞단 은 따로 짜서 링킹하는 방식으로 제작되며 성형 스웨 터와 카디건류가 많다.
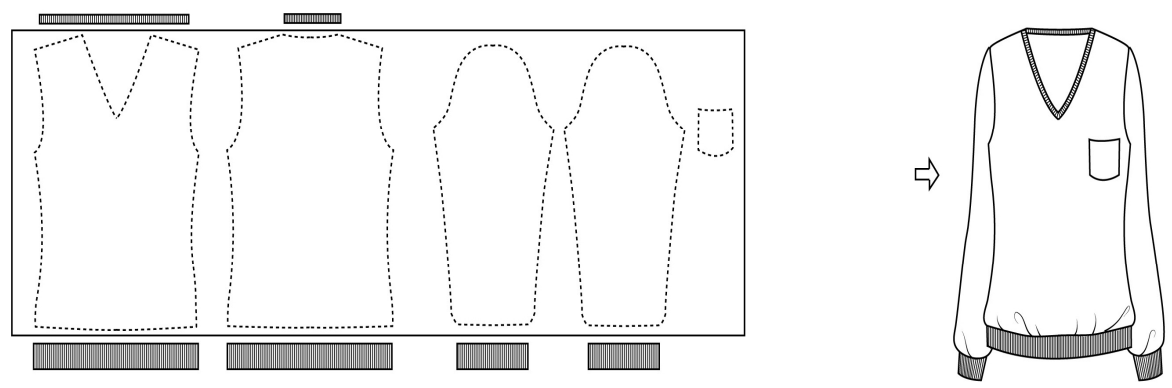

<Figure 1> Knitting Diagram of Cut \& Sew - Knit Design Guide Book, p.154
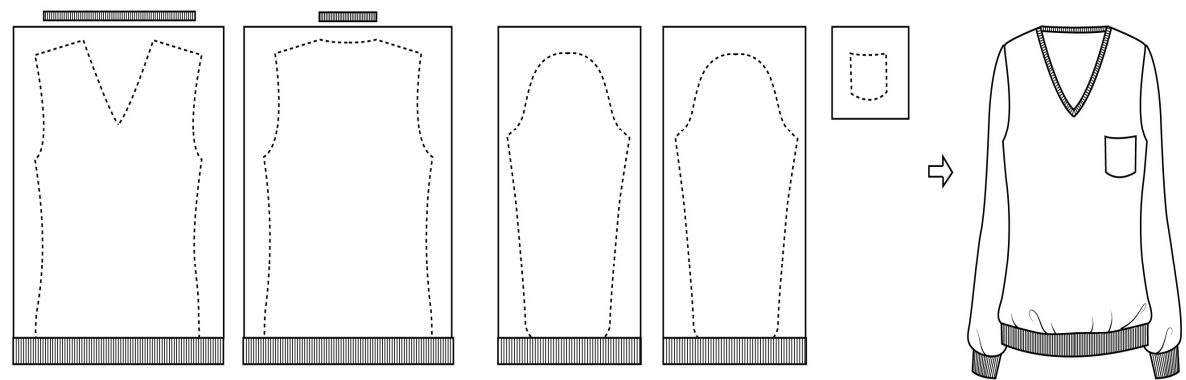

<Figure 2> Knitting Diagram of Cut \& Linking - Knit Design Guide Book, p.154 


\section{3. 풀 패셔닝(Full Fashioning)}

풀 패셔닝은 패턴과 게이지를 미리 계산해서 니트를 편직하는 것이다<Figure 3>. 즉, 패턴에 의하여 코 줄 임이나 코 늘임 조직을 이용하여 패턴대로 편직하고 링킹 봉제를 실시하여 제품을 만드는 방법이다. ${ }^{10)}$ 오 늘날에는 컴퓨터 니트 편기에 의하여 자동적으로 편직 되고 있다. 풀 패셔닝 제품은 네크라인이나 포켓 등과 같은 부속 부분은 링킹 방법에 의하여 연결된다. 풀 패 셔닝 제품은 니트 편직을 패턴에 맞추어서 편직하기 때문에 원사의 로스분이 적어서 생산성이 높다. 편직 할 때 허리 단에서 몸판으로, 소매 부리에서 소매로 연 결하여 편직하므로 재단할 필요 없이 편직 된 끝 부분 이 끝마무리가 되어 풀리지 않으며, 대부분 링킹 머신 에 의해 봉제된다.

\section{4. 인터그랄 니트(Integral Knit)}

횡편기에서 스웨터를 편직하는 경우 일반적으로 앞, 뒤 몸판과 소매 부분만 편직 되던 것에서 더하여 부속
품을 한꺼번에 편직하는 방법<Figure $4>$ 을 인터그랄 니트라고 한다. 칼라, 목둘레선의 부속, 카디건의 앞 단, 포켓 등을 별도로 편직해서 봉제하는 풀 패셔닝 제 품에서 발전된 형태로 몸판과 동시에 부속품들을 함께 편직하는 방법으로 부속품을 연결하는 봉제 공정에 걸 리는 시간이 짧아지게 된다.

\section{5. 무봉제 니트(Seamless Knit)}

무봉제 니트는 편직기계 내에서 한 벌의 옷이 완성 되는 시스템<Figure 5>으로, 봉제과정을 거치지 않고 편직기 내에서 모든 공정이 끝나게 된다. 디자인된 형 태를 따라 성형 편을 편직하면서 종래의 링킹이나 봉 제에 의해서 연결되었던 옆 솔기, 어깨 솔기, 소매 밑 부분, 앞단 부분을 따로 연결할 필요가 없는 완제품 시 스템이다. 국내에서는 무봉제 니트가 곧 홀가먼트1ㅣㄹㅏ 고 인식되어 있다.
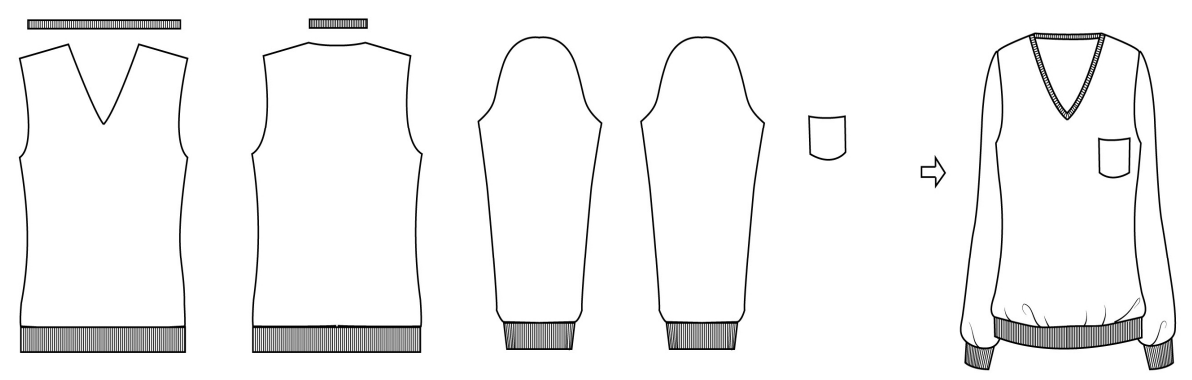

<Figure 3> Knitting Diagram of Full Fashioning - Knit Design Guide Book, p.155
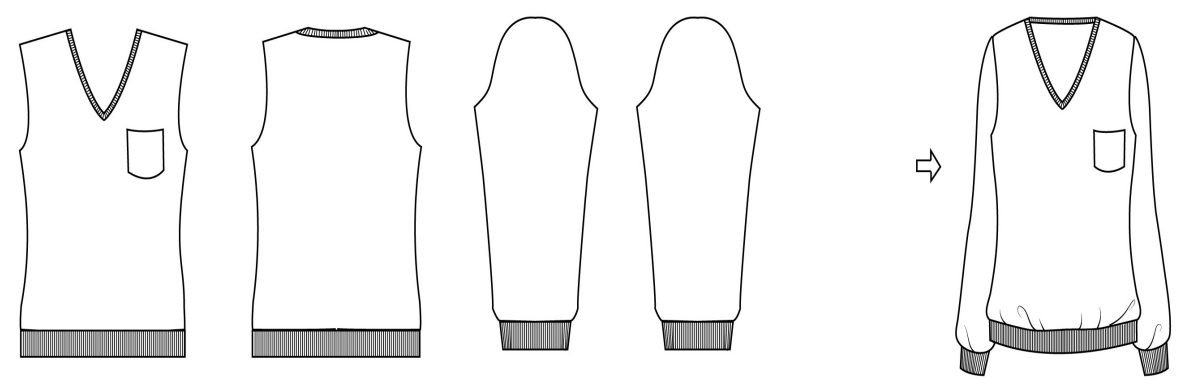

<Figure 4> Knitting Diagram of Integral Knit - Knit Design Guide Book, p.157 


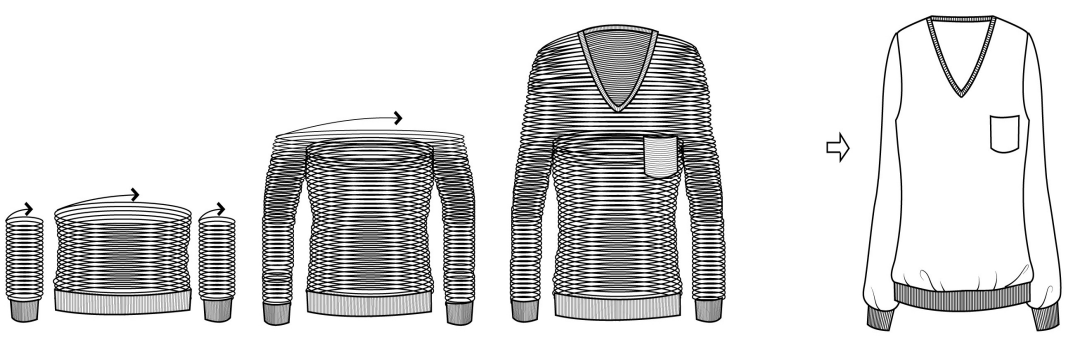

<Figure 5> Knitting Diagram of Seamless Knit

- Reference to KITCEH's Whole Garment Plan and Computer Programming

\section{III. 홀가먼트 니트웨어의 생산 공정과 특징}

\section{1. 홀가먼트 니트웨어의 생산 공정}

\section{1) 디자인 기획}

시즌 트렌드와 브랜드 컨셉에 맞게 디자인을 기획 하여 아이템, 실루엣, 조직, 게이지, 소재, 컬러, 디 테일을 결정하여 작업지시서를 작성한다. 홀가먼트 니트웨어의 특성이 효과적으로 표현되고 생산성 있 는 제품이 되도록 디자인을 기획한다.

\section{2) 프로그래밍}

프로그래머가 작업지시서의 디자인에 맞게 프로그 램을 실시한다. 시마세이키사 홀가먼트 편직기의 프 로그래밍은 크게 두 가지가 있는데, 기본 내장된 아이 템을 기초로 자동적으로 프로그램하는 경우와 사이즈 스펙과 디자인을 가지고 직접 패턴을 만들어 프로그램 을 전개하는 경우가 있다. 프로그래밍 순서<Table 1> 는 첫째, 아이템 및 스타일 선택으로 프로그램 파일 명, 저장위치, 기종, 게이지를 선택하고 디자인하고 자 하는 아이템과 구체적인 스타일을 지정한다. 둘 째, 게이지, 사이즈 설정은 각 부위별로 사이즈를 입 력할 수 있으며 지정된 사이즈를 선택하면 소매와 몸판이 하나로 연결된 패턴으로 제시된다. 셋째, 패 턴 선택은 앞길과 뒷길에 소매가 부착된 상태로 프 로그램 패턴이 나와 형태감을 모니터 상에 보여준 다. 바디, 암홀, 칼라 등 각 부위별로 모양과 조직의 편성을 지정해준다.
홀가먼트 프로그램은 기본, 앞길, 뒷길 패턴 3 개 가 기본 프로그램을 이루고 있다. 조직의 표현은 앞 판과 등판에만 하며 일반 횡편기가 앞길, 뒷길 조직 을 표현하는 색상이 같은데 비해 홀가먼트 편성 프 로그램에서는 앞길, 뒷길 조직을 표현하는 색상이 다르다. 패키지 프로그램은 제작한 기본 실루엣의 패턴을 편기에서 짜는데 필요한 패키지 베이스 패턴 (package base pattern)을 제작하는 것이다. 완성 프로그램은 패키지 프로그램이 연결된 형태로 양 옆 의 옵션라인에 우수 ${ }^{12)}$, 도목 ${ }^{13)}$, 속도 등을 편성할 수 있게 지정하고 편직기에 입력한다. 자동 제어 실행 으로 점프, 우수 등을 체크한 후 시율레이션 과정을 거친 후에 편직에 들어간다.

3) 편직

편직 준비는 편직기에 원사를 셋팅 해 놓고, 완성 된 프로그램을 가지고 디스켓이나 이동식 메모리를 이용하여 편직기에 입력한다. 홀가먼트 니트웨어 편 성기법은 기본적으로 튜블러(tubular)방식 ${ }^{14)}$ 이다. 오 른쪽으로 가면서 뒷길을 편성하고 왼쪽으로 오면서 앞길을 편성한다<Figure 6>. ${ }^{15)}$ 소매와 몸판이 연결 되는 부분까지 편성하고 암홀 시작부분에서는 랙킹 (racking) ${ }^{16)}$ 동작이 따로 편성되던 소매와 몸판을 연 결해 준다. 소매와 몸판이 연결된 다음에는 다시 튜 블러 방식의 편성이 이루어진다. 목 파임 부분은 앞 트임의 한쪽만을 편성하고 뒤를 전체적으로 편성하 면서 트임 반대쪽으로 가서 또 다른 쪽을 편성하고 전체적으로 뒤를 편성하는 c-knitting ${ }^{17)}$ 방법으로 편 성된다. 목 부분의 편성이 끝나면 끝 부분이 풀리지 
$<$ Table 1> The Order of Whole Garment Knitting Programming

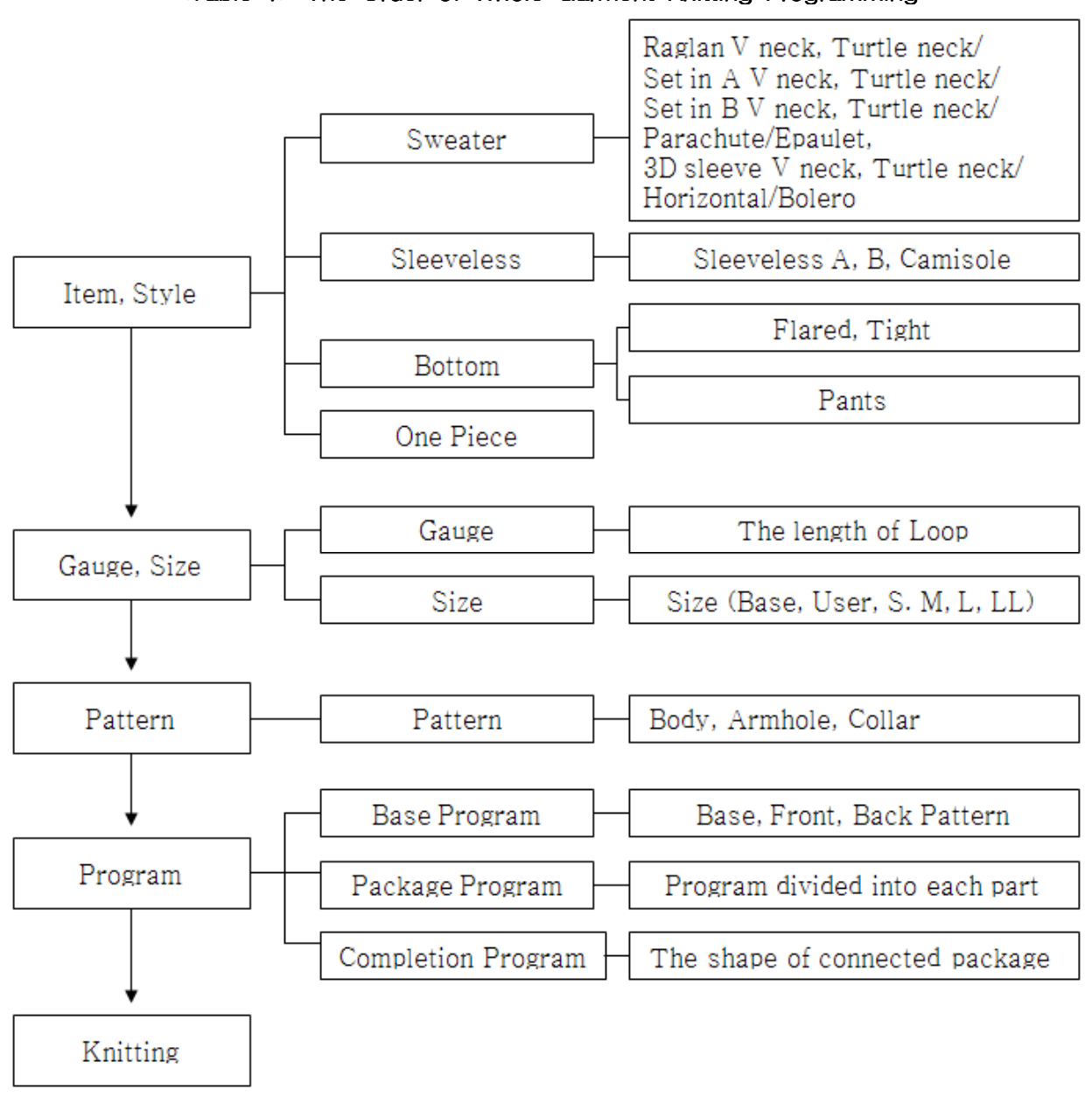

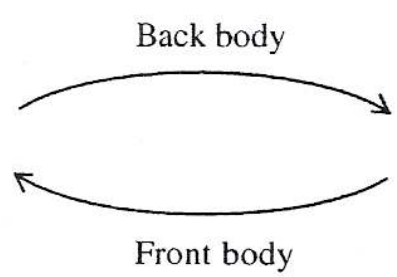

<Figure 6> Formation Direction of Whole Garment

- SWG-X Lecture Notebook(2000), p.19

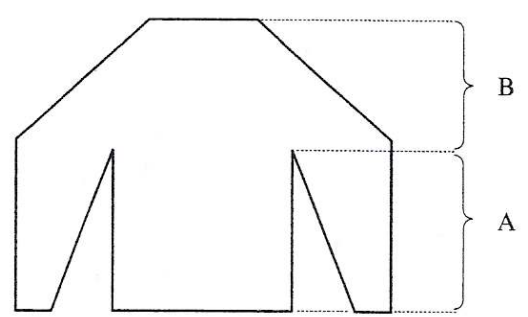

$<$ Figure 7> The number of Organized Carriers in Whole Garment

- SWG-X Lecture Notebook(2000), p.19 
않도록 막음 처리(bind off)를 해준다. 제품과 제품 사이에 연결된 원사를 정리하면 편직이 완료된다. 홀가먼트 편성시 몸판과 소매를 편직할 때 캐리어수 <Figure 7>(8)는 유동적으로 바뀌게 되는데, A구간 은 몸판과 소매가 분리되기 때문에 3 개의 캐리어 ${ }^{19)}$ 로 구성되며 B구간은 1개로 변화된다.

\section{4) 가공 및 완성}

일반적인 홀가먼트 니트웨어 가공 공정은 편직 후 편직물 검사, 봉조 ${ }^{20)}$, 완성 다림질의 단계를 갖는다.
홀가먼트 편기로 편성을 하게 되면 칼라, 앞단, 허리단 부분이 말리거나 약한 단점이 있기 때문에 편직 후 링 킹 ${ }^{21)}$ 과 트리밍 부착 등의 부분 공정이 추가되기도 한 다. 완성 후에 편직 소요시간에 따라 편직료를 산출하 고, 편직에서는 암홀이나 칼라 끝선, 도메 ${ }^{22)}$ 부분의 메 인 생산 시 이상 유무를 체크한다.

홀가먼트 니트웨어의 생산 공정을 단계별로 사진으 로 제시한 <Table 2> ${ }^{23)}$ 는 연구자가 홀가먼트 니트웨 어 생산 공정에 직접 참여하여 그 과정을 촬영한 것이 다.

$<$ Table 2> Whole Garment Knit Wear's Production Processing in Each Step

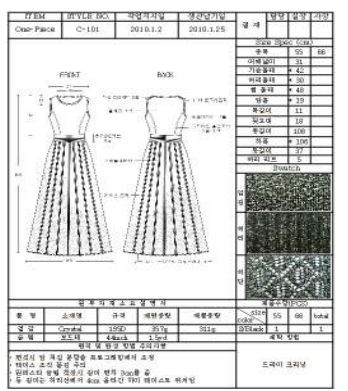

Design Planning

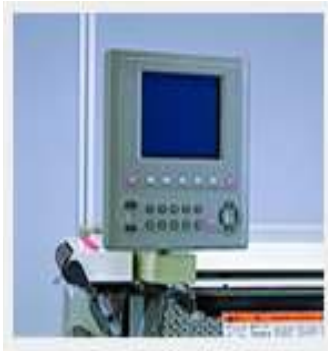

Input Data

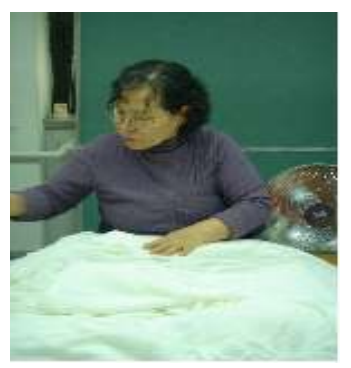

Checking Knitted Textiles

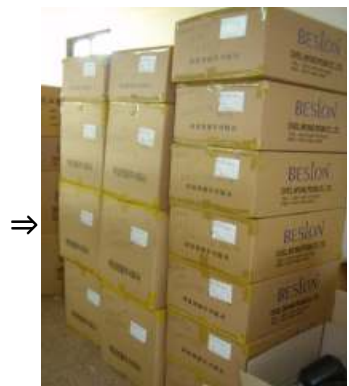

Selection of Yarn

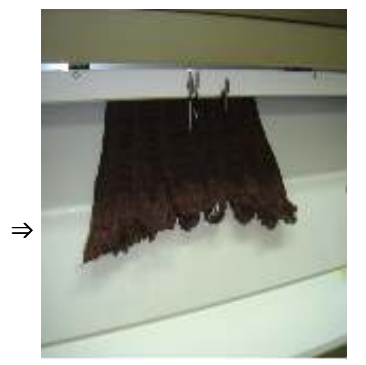

Knitting Process 1 (25min)

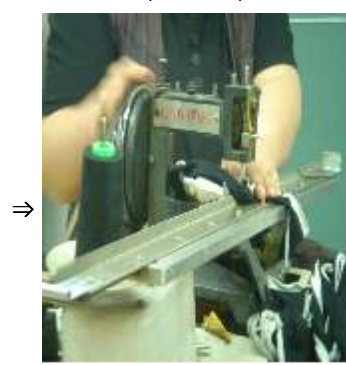

Linking

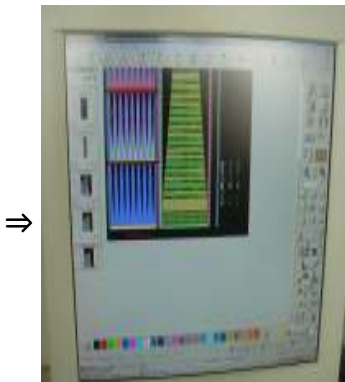

Programming

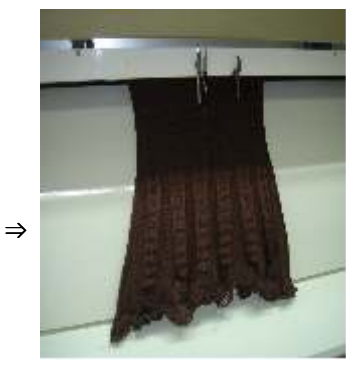

Knitting Process 2 (40min)

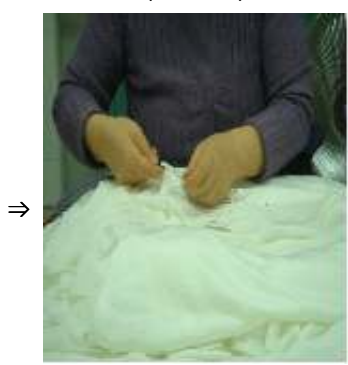

Whipstitch

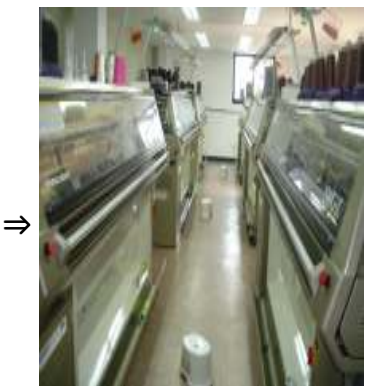

Knitting Machine (SWG-X)

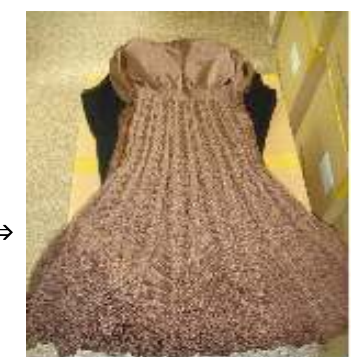

Knitting Process 3 (90min)

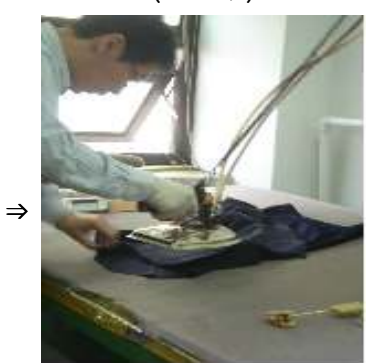

Completion Ironing

- Researcher's Photo Data 


\section{2. 홀가먼트 니트웨어와 일반 니트웨어의 생산 공정 비교}

홀가먼트 니트웨어의 생산 공정과 비교하기 위해 ॥ 장에서 살펴본 컷 앤 소, 컷 앤 링킹, 풀 패셔닝, 인터
그랄 니트웨어의 생산 공정을 비교하여 살펴보면 $<$ Table 3>와 같다.

홀가먼트 니트는 생산 공정이 가장 단순화된 제품으 로 원사 선택, 프로그래밍, 편직, 편직물 검사, 봉조, 완성 다림질의 단계를 거쳐 생산된다. 컷 앤 소, 컷 앤

$<$ Table 3> The Comparison of Knit Wear Production Process

\begin{tabular}{|c|c|c|c|c|c|c|}
\hline \multicolumn{2}{|c|}{$\begin{array}{l}\text { Production } \\
\text { Process }\end{array}$} & Content & $\begin{array}{c}\text { Cut \& } \\
\text { Sew } \\
\text { Cut \& } \\
\text { Linking }\end{array}$ & $\begin{array}{c}\text { Full } \\
\text { Fashioni } \\
\text { ng }\end{array}$ & $\begin{array}{c}\text { Integral } \\
\text { Knit }\end{array}$ & $\begin{array}{l}\text { Whole } \\
\text { Garment }\end{array}$ \\
\hline \multicolumn{2}{|c|}{ Selection of yarn } & Select yarn according to design & O & O & O & O \\
\hline \multicolumn{2}{|c|}{ Pattern making } & Produce pattern considering fabric's elasticity & O & O & O & $x$ \\
\hline \multicolumn{2}{|c|}{ Programming } & Proceed programming selected pattern and structure & O & O & O & O \\
\hline \multicolumn{2}{|c|}{ Knitting } & $\begin{array}{l}\text { Cut \& Sew : Knitting in the form of fabric } \\
\text { Cut \& Linking : Knitting each of front, back, sleeve, } \\
\text { and collar }\end{array}$ & O & O & O & O \\
\hline \multicolumn{2}{|c|}{$\begin{array}{c}\text { Checking knitted } \\
\text { textiles }\end{array}$} & $\begin{array}{l}\text { Check salt stains, contamination, density, size, drop } \\
\text { stitch }\end{array}$ & O & O & O & O \\
\hline \multicolumn{2}{|c|}{$\begin{array}{l}\text { Ironing knitted } \\
\text { textiles }\end{array}$} & Smooth out ply and veining & O & O & $\triangle$ & $x$ \\
\hline \multicolumn{2}{|c|}{ Cutting } & $\begin{array}{l}\text { Cut according to pattern including seam allowance } \\
\text { and cut according to size deviation and amount }\end{array}$ & O & $x$ & $x$ & $x$ \\
\hline \multirow{3}{*}{$\begin{array}{l}\text { Proce } \\
\text { ssing }\end{array}$} & Overlock & $\begin{array}{l}\text { Overlock on seam allowance so that ply at the end of } \\
\text { fabric does not become untangled }\end{array}$ & O & $x$ & $x$ & $x$ \\
\hline & $\begin{array}{l}\text { Lock } \\
\text { stitch }\end{array}$ & $\begin{array}{l}\text { Used in sewing-process necessary design that does } \\
\text { not require elasticity such as sideline, collar, dart, and } \\
\text { interlining }\end{array}$ & 0 & $x$ & $x$ & $x$ \\
\hline & Linking & $\begin{array}{l}\text { Used in design that requires linking such as collar, } \\
\text { front, pocket, and shoulder }\end{array}$ & 0 & 0 & 0 & $\triangle$ \\
\hline \multirow{2}{*}{\begin{tabular}{c|} 
Whipst \\
itch
\end{tabular}} & Whipstitch & $\begin{array}{l}\text { Whipstitch directly with hands at the end of linking } \\
\text { and seam allowance }\end{array}$ & 0 & 0 & 0 & 0 \\
\hline & Buttoning & $\begin{array}{l}\text { Use color that fits fabric, make button holes in } \\
\text { straight or } Q Q \text { pattern, and put on buttons }\end{array}$ & 0 & 0 & $\triangle$ & $\triangle$ \\
\hline \multicolumn{2}{|c|}{$\begin{array}{l}\text { Completion } \\
\text { Ironing }\end{array}$} & $\begin{array}{l}\text { Ironing that requires three-dimensional shape is } \\
\text { utilized in outer, and mold ironing is completed when } \\
\text { it is put in suitable mold }\end{array}$ & 0 & 0 & 0 & 0 \\
\hline
\end{tabular}

* $\mathrm{O}$ : Processed, $X$ : Not Processed, $\triangle$ : Either Processed or Not 
링킹 공정은 일반적인 공정을 다 필요로 하지만, 풀 패 셔닝, 인터그랄 가공 공정은 성형으로 편직하기 때문 에 재단과 가공의 일부 공정이 생략되어 진행된다. 인 터그랄 공정에서 편직물 다림질 공정을 거치지 않는 경우가 있고 포켓이나 단추 구멍 등을 편직과정 중에 처리하기도 하므로 표에서 ' $\triangle$ '로 표기 하였다.

홀가먼트 니트는 별도의 패턴 메이킹 과정을 거치지 않고 프로그래밍 과정 중 패턴과 조직이 결정되므로 공정이 보다 간편하다. 또한 풀 패셔닝, 인터그랄 니트 공정의 편성물 다림질이나 링킹과 같은 가공 과정이 생략되어 더욱 단축된 공정을 보여준다. 홀가먼트는 링킹이나 단추 달이와 같은 공정이 디자인에 따라 있을 수도 있고 없을 수도 있기 때문에 ' $\triangle$ '로 표기 하였다. 홀가먼트 편기로 편성을 하게 되면 칼라, 앞 단, 허리 단 부분이 말리거나 약한 단점을 가지고 있기 때문에 필요에 따라 편직 후 부분 공정이 추가되기도 한다.

\section{3. 홀가먼트 니트웨어 제품의 특징}

홀가먼트 니트웨어는 니트 제품의 디자인 개발에 있어서 소비자의 요구에 부응할 수 있는 경쟁력 있 는 니트 제품의 생산을 가능하게 한다.

\section{1) 착장 측면}

기계에서 한 벌의 옷이 완성되는 홀가먼트 니트웨 어는 어깨나 옆선의 시접이 없어 가볍고 착용감이 뛰어나며 몸과 함께 움직이는 느낌을 주게 된다. 홀 가먼트 니트는 니트 본래의 특징을 십분 살린 이상 적인 니트웨어로 ${ }^{24)}$ 봉제라는 연결고리가 없어 마치 '제2의 피부'처럼 완벽한 착용감을 준다. 특히 몸판 과 소매가 봉제선이 없이 연결되어 팔 동작이 편안 하고 안락감을 준다. 이러한 특성은 피부자극에 민 감한 노약자나 유·아동을 위한 제품 개발에 있어 큰 장점이 될 수 있다.

2) 생산 측면

홀가먼트 편기는 스티치, 연결, 그리고 봉제를 생략 한 $3 \mathrm{D}$ 무봉제 니트의 생산을 가능하게 한다. ${ }^{25)}$ 일반적
인 니트웨어의 편직 시 디자인에 따라 재단 로스분이 20 40\%까지 발생하게 되는데, 홀가먼트는 재단 자체 가 필요 없는 시스템으로 원자재에 대한 실의 로스 (loss)와 봉제공정을 줄여 납품 시간을 단축할 수 있 다. 또한 봉제 공정이 없기 때문에 인건비를 줄일 수 있다.

컴퓨터 제어에 의해 전 공정을 일관되게 관리, 생산 하므로 균일한 품질을 유지하여 품질 향상이 가능하 다. 또한 스팟 및 기획생산으로 인해 판매처에서의 상 품 회전율 및 판매 소진율에도 기여할 수 있다. 동시에 다품종 소량생산과 반응 생산, 필요한 제품을 필요한 수량만큼 생산하는 QR시스템의 실현에도 적합하다. 이처럼 홀가먼트 니트는 지금까지의 노동 집약적 산업 형태에서 기획 제안형, 지식 집약 산업으로의 전환을 가능하게 한다.

그러나 홀가먼트 니트의 기계설비 투자비용이 일반 횡편기의 2 배 정도 되기 때문에 국내 홀가먼트 편직 업체 수는 매우 적은편이다. 기계 투자비용이 높기 때운에 자연히 편직료가 높아지고 이것은 곧 생산력 저하로 이어지게 된다. 이러한 이유로 홀가먼트는 국내 니트 제품 중에 차지하는 비중이 적어 국내 소 비자에게 홀가먼트 니트웨어의 인지도가 낮은 실정 이다.

3) 환경 측면

홀가먼트 니트는 재단과 봉제과정이 없어 불필요한 원사 또는 원단의 낭비나 환경오염을 줄일 수 있고 쾌 적한 삶에 대한 현대인들의 욕구에 부합하며 저탄소 녹색성장에 기여할 수 있는 환경 친화적 제품이라 할 수 있다.

이와 같은 생산 공정을 통해 본 홀가먼트 니트웨어의 특징을 정리하면 <Table 4>과 같다.

\section{IV. 홀가먼트 제품 개발 사례}

\section{1. 디자인 기획}

홀가먼트 니트는 살펴본 바와 같이 봉제선이 없는 제품의 특성으로 인해 착용성 측면에 볼 때 피부가 
$<$ Table 4> The Characteristics of Whole Garment Knit Wear

\begin{tabular}{c|l}
\hline \hline Division & \multicolumn{1}{c}{ Characteristics } \\
\hline Wearing & - Light and excellent wearing comfort due to absence of seam allowance \\
Perspective & - Excellence elasticity and activity due to absence of sewing line \\
& - Added value as whole garment product \\
\hline & - Avoid labor due to unnecessary processing line \\
& - Reduce the original cost due to reduced processing time \\
& - Suitable for diverse-kind and less-quantity production \\
Producing & - Suitable for QR production due to reduced period of delivery \\
Perspective & - Quality improvement due to computer control and consistent production \\
& - High investment in machine equipment and low productive capacity due to the \\
& - Small number of companies \\
\hline Environmental & - Protection of the environment due to yarn reduction \\
Perspective & - Environment-friendly due to reduced fabric waste \\
\hline \hline
\end{tabular}

약한 유, 아동이나 노약자들에게 적합한 장점이 있 다. 조형적 측면에서 볼 때에는 자연스러운 3차원의 형태 표현이 용이하기 때문에 부드럽고 자연스러운 라인의 표현이 가능하다. 본 연구는 홀가먼트의 생 산공정을 살펴보고 이에 따른 제품개발의 사례로 고 부가가치를 지닌 패션제품을 개발하는 것을 목적으 로 하기 때문에 디자인 기획의 방향을 홀가먼트 니 트가 지닌 조형적 측면을 강조하는 것으로 설정하였 다.

홀가먼트 니트의 조형적 특징을 부각시키기 위해 '자연스러우면서 정교한 라인(Elaborate Line)'을 디 자인 테마로 선정하였고, 부드럽고 여성스러운 라인 의 표현이 가장 적합한 연령대인 30대 여성을 제품 의 메인 타껫으로 하였다. 크로스 코디 연출을 통해 개성을 표출하는 소비자 집단을 대상으로 하였으며, 현대적인 세련미를 지닌 우아한 여성의 이미지를 연 출하고자 하였다. SWG-X 편기를 사용하여 자연스 러운 코 줄임과 코 늘림으로 자연스러운 피트 앤 플 레어와 인체에 따른 바디라인의 실루엣을 섬세하게 표현하는 것이 디자인의 기획의 핵심 요소이다.

아이템은 크게 슬리브리스 원피스와 오픈 베스트 로 구성하였다. 슬리브리스 원피스는 메탈사가 혼합 된 블랙 Crystal사를 12게이지의 2ply로 편직하며,
몸판은 플레인 조직, 스커트는 레이스 조직을 사용 하여 피트 앤 플레어 라인을 표현하도록 하였다. 오 픈 베스트는 Channet 1500와 실버 메탈사를 합사 하여 12 게이지의 $4 \mathrm{ply}$ 로 편직하고, $1 \times 1$ 조직, 레이스 조직, 코 늘림을 사용하여 자연스러운 A라인 실루엣 을 형성하도록 기획<Table $5>$ 하였다.

\section{2. 프로그래밍 및 편직}

디자인 기획의 내용을 토대로 프로그래밍하고 편 직하였다. 여기서는 슬리브리스 원피스의 프로그래 밍 과정을 대표로 제시하고자 한다.

프로그래밍을 위한 첫 단계는 아이템 및 스타일을 지정하는 것으로 프로그램 파일의 '새로 만들기'에 서 원피스, SWG-X 기종, 12 게이지를 선택한다. 다 음 단계는 사이즈를 설정하는 것으로, 가슴둘레 $46 \mathrm{~cm}$, 암홀 $20 \mathrm{~cm}$, 목파임 $12 \mathrm{~cm}$, 총길이 $103 \mathrm{~cm}$ 등 사이즈를 각 부위별로 입력한다.

프로그래밍을 위한 아이템과 스타일, 사이즈와 같 은 기초자료의 입력이 끝나면 구체적인 패턴 선택을 실시한다. 패턴은 앞길과 뒷길이 부착된 상태로 프 로그램 패턴이 나와 형태감을 모니터 상에서 확인 할 수 있다. 바디, 암홀, 스커트 등 각 부위별 편성 
이인숙 - 조규화 - 김지영 / 홀가먼트의 생산 공정과 니트웨어 개발 사례

$<$ Table 5> Elaborate Line Design Plan

\begin{tabular}{|c|c|c|c|c|c|}
\hline Item & Silhouette & Color & Structure & Yarn & Gauge \\
\hline One Piece & Fit \& Flare & $\begin{array}{c}\text { Black (Pantone } \\
\text { 19-0508TP) + } \\
\text { Silver (Pantone } \\
\text { 14-5002TP) }\end{array}$ & $\begin{array}{c}\text { Plain } \\
+ \\
\text { Lace }\end{array}$ & $\begin{array}{c}\text { Crystal } \\
\text { (Rayon 85\%, } \\
\text { Polyester 15\%) }\end{array}$ & $\begin{array}{l}12 \mathrm{G} \\
2 \mathrm{ply}\end{array}$ \\
\hline Vest & A Line & $\begin{array}{l}\text { White (Pantone } \\
\text { 11-0601TP) + } \\
\text { Silver (Pantone } \\
\text { 14-5002TP) }\end{array}$ & $\begin{array}{c}\text { Lace } \\
+ \\
1 \times 1\end{array}$ & $\begin{array}{c}\text { Channet } \\
\text { (Acrylic 100\%) } \\
\text { 3ply } \\
\text { Metal } \\
\text { (Rayon 85\%, } \\
\text { Polyester 15\%) } \\
\text { 1ply }\end{array}$ & $\begin{array}{l}12 \mathrm{G} \\
4 \text { ply }\end{array}$ \\
\hline
\end{tabular}

방법을 결정하며 플레인, 레이스 조직을 지정해준다. Elaborate Line 원피스의 홀가먼트 편직 프로그램은 기본 패턴, 앞길과 스커트 패턴, 뒤 길과 스커트 패 턴의 3 개의 패턴이 기본 프로그램을 이루게 된다 <Figure 8>.

완성 프로그램은 패키지 프로그램이 연결된 형태 로 양 옆의 옵션라인에 우수, 도목, 속도 등을 편성 할 수 있게 지정하면 되는데 <Figure 9>는 완성된 프로그램을 보여주는 것이다. 완성된 프로그램으로 편직할 수 있도록 자동 제어 변수<Figure 10>에서 확정 데이터 값을 지정해주고, 각각의 색상과 원사 에 맞게 우수를 지정해준다. 편직성이 좋도록 풀다 운 값 을 지정해주고, 캐리어의 위치 등을 지정한 후 저장한 프로그램을 디스켓을 활용하여 편직기계 에 입력하면 실제 편직기에서 편성이 이루어지게 된 다.

\section{3. 완성}

1) Elaborate Line 원피스

피트 앤 플레어 실루엣의 우아한 원피스<Figure $11>$ 로 플레인 조직으로 편직한 암 워머와 함께 매
치하여 우아한 분위기를 연출하도록 하였다. 원피스 의 목선과 암홀에 리브조직을 제끝 처리하였고 몸판 은 플레인 조직으로 형태의 안정성을 주었다. 몸판 의 프린세스 라인에 2줄의 펄편 조직으로 다트라인 을 주어 변화감을 주었다. 허리선은 제 허리에서 $4 \mathrm{~cm}$ 올라간 하이 웨이스트로 처리하여 하체가 길어 보이도록 하였으며 허리라인은 $5 \mathrm{~cm}$ 높이의 $2 \times 2$ 리 브로 처리하였다. 스커트 부분은 마름모 모양의 레 이스 조직과 리브 조직을 믹스하여 16 개의 주름을 만들어 플레어 부분을 처리하였으며, 잍단은 터크 조직으로 여성스럽게 표현하였다. 편직 시 앞 처짐 분량은 프로그래밍에서 조정하였다.

2) Elaborate Line 베스트

앞이 오픈된 형태로 자연스런 표면감을 나타내는 $\mathrm{A}$ 라인 실루엣의 베스트<Figure 12>0닫. 앞단에는 자연스러운 드레이퍼리 효과를 주어 여성스러운 느 낌을 주었고, 짧은 칼라로 멋스러움을 더해 주었으 며 같은 재질감의 허리끈 장식으로 마무리 하였다. 메탈사를 합사하여 시원하면서도 고급스러운 이미지 를 주고자 하였고 플레인과 $1 \times 1$ 리브 조직을 옆선 라인에 배치하여 슬림하게 보이게 하였다. 앞단은 
플레인 제끝으로 자연스러운 말림이 표현되도록 하 였고, 앞단은 플레인 조직과 코 늘림 조직으로 드레 이퍼리를 만들어 헴 라인에 변화를 주었다. $17 \mathrm{~cm}$

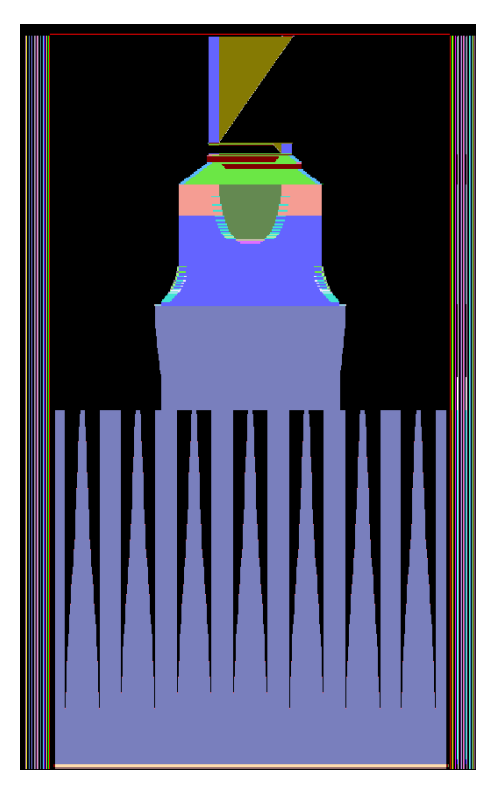

base pattern

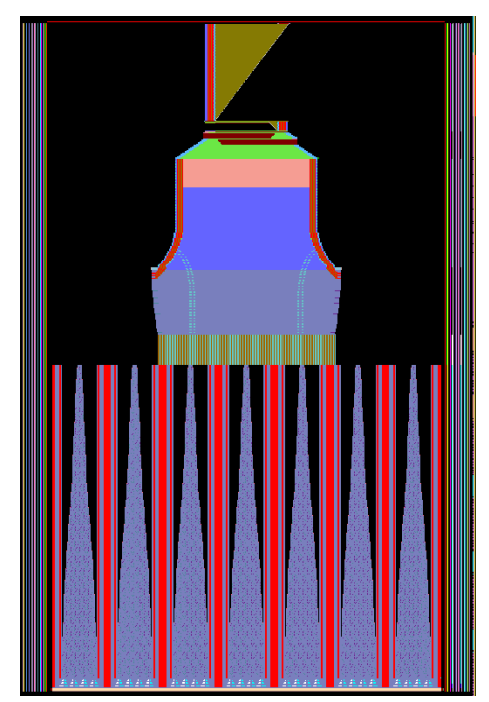

back \& skirt pattern
높이의 하단은 레이스 조직으로 가볍고 시원한 느낌 으로 연출하였고, 스탠드 칼라는 튜블러 조직을 사 용하여 힘이 있도록 처리하였다.

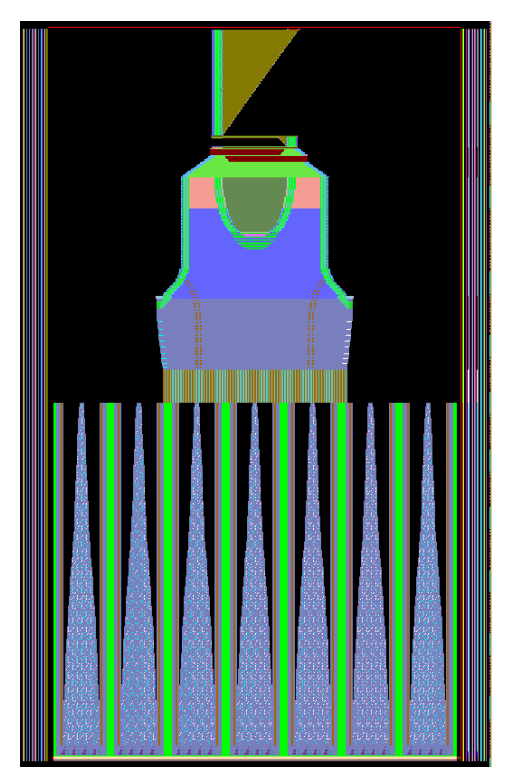

front \& skirt pattern

<Figure 8> Elaborate Line One-Piece (base, front, back pattern)

- Researcher's Photo Data 


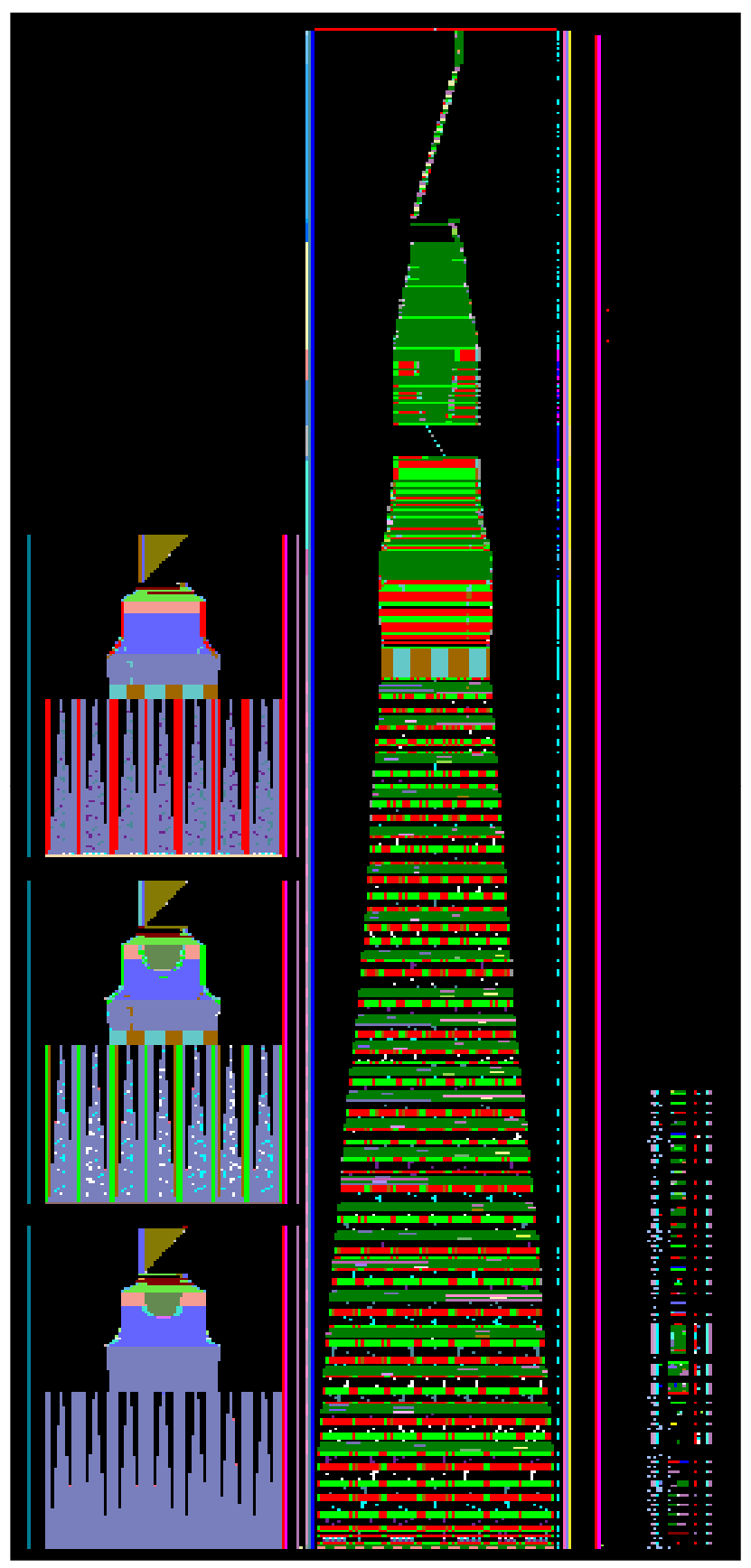

<Figure 9> Elaborate Line One-Piece Completion Program

- Researcher's Photo Data 


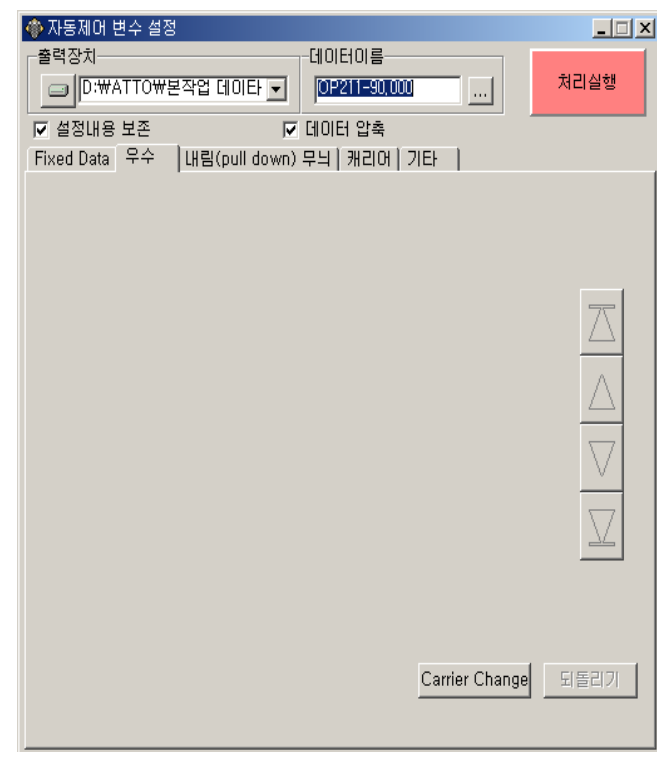

tarn carrier

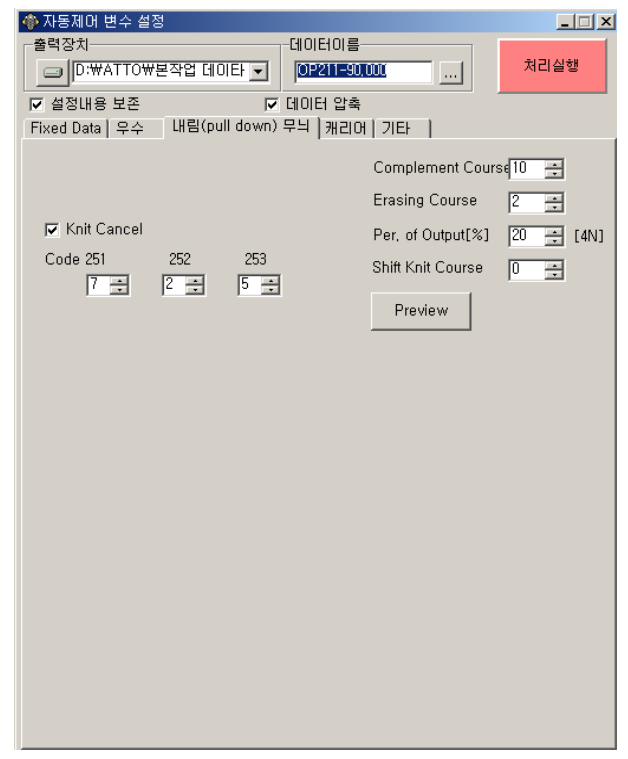

pull down

$<$ Figure 10> Elaborate Line One-Piece Automatic Control (tarn carrier, pull down)

- Researcher's Photo Data

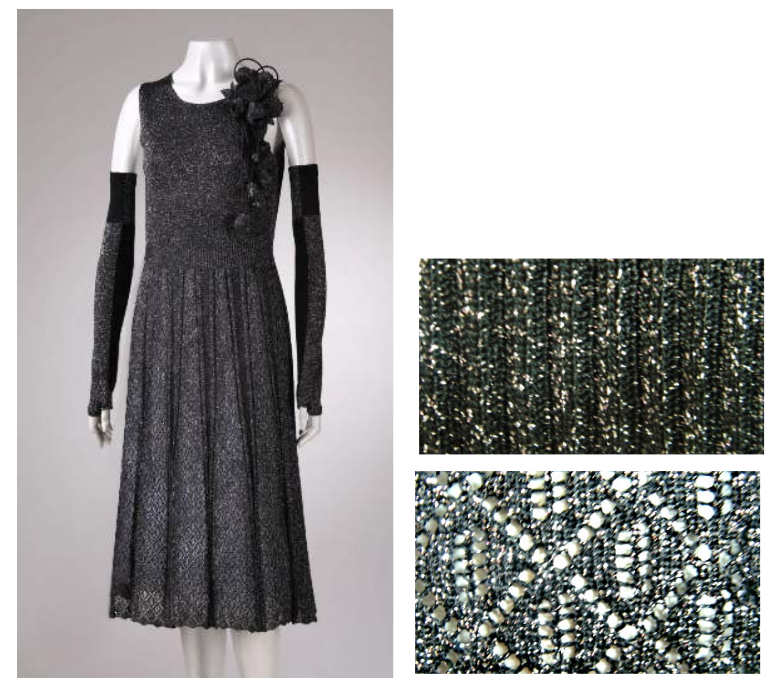

<Figure 11> One-Piece dress(left), Structure(right)(up: waist rib, down: skirt lace) 
이인숙 - 조규화 - 김지영 / 홀가먼트의 생산 공정과 니트웨어 개발 사례

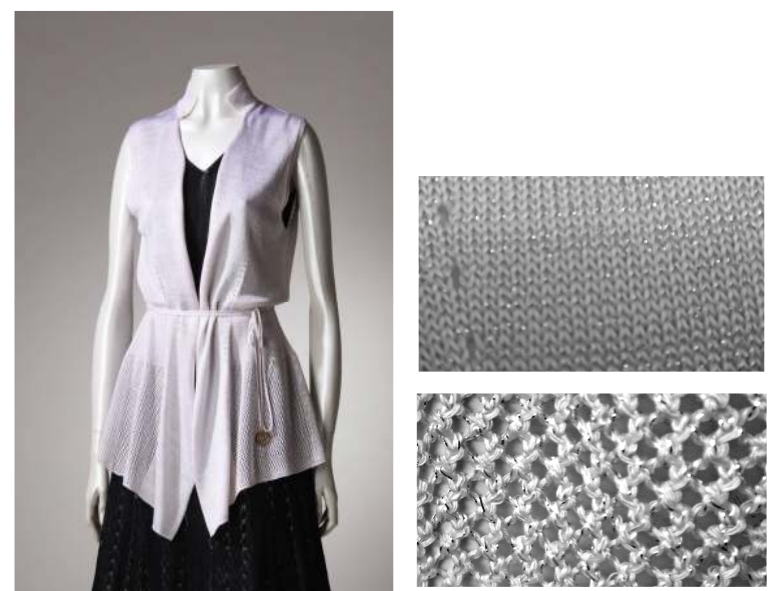

<Figure 12> Vest(left), Structure(right)(up: plain, down: lace)

\section{V. 결 론}

홀가먼트 니트웨어는 편직기계에서 한 벌의 옷이 완성되어 봉제과정을 거치지 않고 나오는 제품으로 21 세기 편직기술의 정점에 선 기술력과 현대인의 감 성을 겸비한 니트웨어이다.

홀가먼트 니트웨어의 생산 공정은 크게 디자인 기 획, 프로그래밍, 편직, 가공 및 완성의 단계로 이루 어진다. 트렌드와 컨셉에 맞게 디자인을 기획한 후 편직 프로그래밍의 순서에 따라 아이템 및 스타일, 게이지, 패턴을 선택한 후 프로그램 과정을 거친다. 편직은 튜블러 방식이 일반적이며 c-knitting 방법으 로 편직 되며 봉조, 완성 다림질을 거쳐 제품이 완 성된다.

홀가먼트 니트웨어의 특징은 첫째, 착장 측면에서 봉제선이 없는 특성으로 인해 착용감과 활동성이 매 우 뛰어나다. 둘째, 생산 측면에서 노동 집약적 작 업 탈피, 가공기간의 단축으로 원가절감이 가능하며 컴퓨터 제어로 일괄된 생산과 품질향상이 가능한 장 점이 있으나 높은 기계 설비 투자비율과 고가의 편 직비용이 단점이라 할 수 있다. 셋째, 환경 측면에 서 봉제, 재단 과정의 생략으로 원사가 절감되고 재 단 폐기물이 감소되어 환경 친화적인 특성이 있다.

홀가먼트 생산 공정에 따라 제품개발을 실시하였
고, 홀가먼트 니트의 특징을 부각시킬 수 있도록 자 연스럽고 섬세한 라인이 드러날 수 있도록 'Elaborate Line'을 디자인 테마로 하여 슬리브리스 원피스와 오픈 베스트를 개발하였다.

이상과 같이 홀가먼트의 생산공정과 이를 통한 제 품 개발에 의해 도출한 본 연구의 결론은 다음과 같 다. 첫째, 홀가먼트 니트는 시접이 없는 자연스러운 연결을 통해 몸과 일체되어 보이는 세련된 룩을 표 현하기에 적합하며 특히 자연스러운 플레어 라인의 표현이 탁월하다. 둘째, 홀가먼트 니트웨어는 일반 니트웨어 생산 공정과는 달리 패턴, 재단, 가공의 단계를 거치지 않기 때문에 반응생산에 매우 적합하 며, 컴퓨터 제어에 의해 전 공정이 일관되게 관리되므 로 지금까지의 노동 집약적 산업 형태에서 벗어나 기 획 제안형 산업으로의 전환을 가능하게 하는 최첨단의 패션영역이라 할 수 있다. 셋째, 프로그래밍 과정을 통 해 디자인을 쉽게 접근 할 수 있으며 다양한 패턴 전개 가 가능하여 고부가가치 니트제품 생산에 적합하다.

이처럼 홀가먼트 니트웨어는 미래지향의 최첨단 니트웨어이지만 국내 니트웨어 시장에서 점유 비중 이 적다보니 숙련된 니트 프로그램 전문가가 부족한 실정이다. 홀가먼트 니트웨어의 프로그램 교육을 통 해 전문가를 육성한다면 국내 홀가먼트 니트웨어의 영역이 확장될 수 있을 것이다. 또한 홀가먼트 니트 
제품의 전략적 마케팅 정책이나 국가적 지원 사업 등을 통해 홀가먼트의 장점을 적극적으로 홍보한다 면 국내에서 홀가먼트 편기의 수요가 늘어나고 제품 의 단가가 내려가게 되어 홀가먼트 니트웨어의 소비 자 접근성이 더욱 높아질 수 있을 것이다. 홀가먼트 니트웨어의 발전과 성장을 통해 국내 니트웨어의 고 부가가치화와 나아가 한국패션의 활성화가 이루어질 수 있기를 기대한다.

\section{Reference}

1) Cho Kyuhwa(1995), Fashion Dictionary, Gyungchunsa, p.332. Seam means the line that connects, seam allowance, seam, stitch, and the parts of clothes, and seamless means there is no connecting line with seam allowance

2) Korean Trade Commission, Korean Apparel Industry Association(2005), Knit Wear Industry Competitiveness Investigation, Trade Commission, p.35.

3) ITMA(International Exhibition of Textile Machinery) first held in 1951 is a textile machine industry field exhibition that is hosted by CEMATEX.

4) Whole Garment Knitting Machines MACH2X, MACH2S, SWG041N, 061N, 091N, SWG-X, SWG-FIRST, SWG-V, SES-S.WG, SES-C.WG made by Shima Seiki, a Japanese company

5) Kim Gunho, et al.(2005), Foreign Market Trend on Knit Material, Korea Textile Development Institute, p.2.

6) Korea Textile Industry Association, et al.(2004), Sweater Technique textbook, Oxygen Project, p.146.

7) "Shima Seiki's 'Whole Garment' selected as spacesuit", (2008. 3. 10), Korea Textile Newspaper, Searched Date 2010. 1. 10,
Source http://www.ktnews.com

8) Hong Myunghwa, et al.(2009), Knit Design Guide Book, Gyungchunsa, pp.152-158.

9) Brackenbury Terry(1992), Knitted Clothing Technology, Oxford: Blackwell Scientific Publications, p.10.

10) Ibid., p.15.

11) Ito Hidesaburo(2003), New Knit Dictionary, Tokyo Knit Fashion Association, p.248.

12) Equipment that drags yarn in order to knit in yarn carrier

13) The length of Loop

14) The structure that makes a space like a pocket between the front and back sides

15) SWG-X Lecture Notebook(2000), Shima Seiki Mfg., Ltd, p.19.

16) Moving needle to left and right several stitches

17) While organizing whole garment knit wear in the field, forming knit direction in $C$ shape when the front side of body is open

18) Ibid., p.19.

19) The equipment that moves needles higher or lower by moving the top part of needle in flat-knitting machine and that dispatches yarn

20) Whipstitching directly with hands at the end of linking and seam allowance

21) Stitch used to connect appendages such as neck line and armhole is called "Sasi" in the field term. In machine shapes, there are dial linking and straight pattern linking machine.

22) The structure that makes a space like a pocket between front and back when knitted to prevent stitches from untangling in the bottom line of sweater as casting

23) The photo data of whole garment production processing taken in the field by me

24) Korea Textile Industry Association, et al.(2004), op.cit., p.146. 
이인숙 - 조규화 - 김지영 / 홀가먼트의 생산 공정과 니트웨어 개발 사례

25) Choi Wonseok, B Nancy(2005) "Three Dimensional Seamless Garment Knitting on V-bed Flat Knitting Machines," Journal of Textile and Apparel Technology and Management, 4, p.29.

접수일(2012년 11월 5일), 수정일(1차 : 2012년 12월 7일),

게재확정일(2013년 1월 4일) 